thank Dr. Unna, that I wish to call attention. The case otherwise points very strongly to the possibility of a localisation of the disease in the skin. The complete restoration of sensation to patches in which the sensibility had been destroyed indicates that, when the disease has not lasted long, a regeneration of nerve fibres may take place within a comparatively short time after the bacilli have been destroyed. The theory of the action of pyrogallic acid in cases like this is probably that it kills the bacilli of leprosy, and the complete cessation of any other manifestation of the disease would indicate that, so far, the bacilli had only obtained hold of the superficial parts of the skin.

The patient was afterwards carefully examined on several occasions, and at considerable intervals, after every appearance of the disease had ceased, and no recurrence was found. Recovery was complete. For a number of years the patient has led an active useful life, enjoying excellent health.

\section{ON OPERATING ON THE SUBJECTS OF EXOPHTHALMIC GOITRE.}

By J. DELPRATT HARRIS, M.R.C.S., Senior Surgeon, Royal Devon and Exeter Hospital.

Nот a great deal seems to have been written on this particular subject. One turns to works on medicine, and finds the disease : carefully described, and attention drawn to many curious nerve manifestations, and the treatment found beneficial in certain milder forms, ending with physical and mental rest, good food, and the avoidance of all stimulants, such as alcohol and coffee. The case now brought forward serves to show what may happen if all these points are obliged to be set aside.

In many surgical works no notice seems to have been bestowed on the subject apart from operating on the enlatged thyroid gland itself. In this last instance a recent work states that such operations not infrequently end fatally in forty-eight hours, the patient becoming delirious and restless this has been attributed to the autotoxic action of the thyroid gland, the patient suffering in a manner similar to that:when too large a quantity of thyroid extract is given.

\section{Case.}

A noman, married, aged 46 , of well-nourished appearance, and not particularly apæmic came to the Royal Devon and Exeter Hospital for pain in her left breast of about a fortnight's duration. She was the subject also of exophthalmic goître. Twenty-three years ago she was confined of twins who were not suckled as she had no true nipples. A fortnight prior to admission she noticed pain of a stabbing character in the left breast, which at the same time she thought began to swell. Her goîtrous condition seems to have caused her no special symptoms, as she can only remember suffering from indigestion and "bile" of late years. Handling the breast caused no pain; a lobulated mass was to be felt in the upper part. It slipped to some extent under the fingers, and was close to the nipple. It seemed about $2 \frac{1}{2}$ inches in diameter; the mammar gland itself seemed swollen, and some general mastitis was present.

The pulse, seldom below 150, was irregular but forcible. There were distinct tremors, and Graefe's symptom was well marked. The date of the onset of the goîtrous symptoms was unknown, but she had been told that her pulse was very quick for at least twenty years. She was kept under treatment at the hospital for quite one month, taking potassium iodide with ammonia, and using extract of belladonna in compound mercury ointment locally. Under this treatment the mastitis certainly diminished, but this only served to bring the hard lobulated masses into greater prominence. As she lived a long distance in the country and
could not come up to be seen easily, after much consideration its removal was decided on, and this was carried out on March oth by Halsted's method. The anæsthetic was ether, which was taken with some difficulty, principally from pulmonary causes.

After the operation the notes run as follows :

March 9 th. - Patient has been very sick several times. Dressing required packing. Had sips of hot water. Pulse 126. Temperature normal. During the night was restless and slept but little. March roth. Pulse r6o. Temperature $99.4 .^{\circ} \mathrm{F}$. Sickness stopped. Pulse weakening and quickening : in the evening ryo. Hypodermic injections of strychnine gr. hours. Complained of faintness. No further packing of dressing required. During the night condition of patient remained about the same. very four hours in all. Complained of cold feet. March rith. Patient very weak and restless. Pulse 180 . Temperature $97.8^{\circ} \mathrm{F}$. Profuse perspiration, but hands and feet cold. Hypodermic injections stopped. slept, has taken fifteen ounces of milk. Hypodermic injection given at 4.30 A.M. At 7.35 A.M, the patient died, the pulse for some hours previously eing quite uncountable. She survived the operation 68 hours

This, then, depicts the condition of a patient suffering from well-marked Graves's disease, who from circumstances is obliged to undergo an operation of a formidable character with all its mental disturbance, other than such on the thyroid gland itself.

It would seem that the condition of the heart is from the first the great difficulty ; beating irregularly at great speed, which possibly indicates thin and dilated ventricles, the anæsthetic at once converts chronic compensation into acute embarrassment, whilst the unavoidable loss of blood causes temporary quickening of the already too quick pulsations, causing general weakness and exhaustion, which, owing to the anæsthetic sickness, cannot at first be remedied by food, and thus before compensation an again be restored our patient sinks. Therefore in advanced cases of exophthalmic goître every effort should be made to avert a serious operation; but, if it is absolutely imperative, a course of treatment with remedies of the digitalis class should precede. Should the heart not respond to this treatment, the operation should be reconsidered, for undoubtedly the risk in such cases is of the gravest possible character.

The operation was conducted under the modern aseptic treatment, biniodide solution being the principal antiseptic used. The loss of blood was very moderate after as well as at the operation, so that the pulse and temperature noted would seem to be that of unavoidable conditions when operating on goîtrous patients who have well-marked Graves's disease.

It may be added that the constant mental worry of having a tumour of the breast-which, if not truly malignant at the time, might degenerate at any time and form an opening loth to heal-had great weight in deciding it best on the whole to operate.

The tumour proved cystic, of the dilated duct type, with apparently no intracystic growths and but little solid material outside the cysts, which seemed surrounded by inflamed gland substance.

\section{A CASE OF DESCENDING LANDRY'S PARALYSIS IN A CHILD.}

BY LEONARD A. ROWDEN, M.B., C.M., ! Leeds.

THE following case is especially interesting on account of its rarity :

N. C., a lad, aged ro, came under my care in June, r897, when passing through a severe attack of whooping-cough. In April, 1898, he was attacked by chorea, which lasted about six months, and affected chiefly the muscles of the face, and only to a slight extent those of the upper and lower limbs. Since October, 1898, he has been in good health, and has appeared to be a very active and bright lad, the only thing noticeable being an occasional slight twitching of one side of his face, which I considered a habit imitated from his father, who is affected in the same way. On September I th, rgoo, I was sent for, and obtained the followin history. On September 14 th he slipped about 5 feet into an excavation for a sewer that was being filled in, and then another 5 or 6 feet to the bottom. He jumped out feeling none the worse for his accident, excep for a slight bruise of the left knee. He played about as usual during th day, and in the evening was very active in a game of cricket. He had a good night. On the following day, September $1_{5}$ th, he did not feel very well, but got up and played about for some hours and took his food as usual. There was no vomiting and no pain or stiffness anywhere, but towards evening he held his head as though he had a slight stiff neck, and vomited once after having some light food. He was rather restless during the night. On September r6th he was up most of the day, but ess during the night, and appeared to be feverish.

Condition on Examination.

On September r7th I saw him about $120^{\prime}$ 'clock. His temperature was nearly $103^{\circ} \mathrm{F}$, his pulse 100 and good, and respiration normal, He dio not appear to be at all ill, having no headache and no pain anywhere. O examination I found that he could not turn his head to either side, bu could move it backwards and forwards. Passive movement of the head was easy, and free from pain. There was also inability to raise either arm at the shoulder-joint. He had a fair grasp with both hands, and could flex and extend the forearms readily at the elbow-joints, and could kick his legs about briskly. There was no bruising or any sign of injury or dislocation at any point of the spine, and no tenderness on pressure of the vertebræ. There seemed to be very slight swelling about the lumbar muscles, but it was not at all distinct, and pressure here seemed to cause a little pain. I considered his condition as probably arising from from the shake of his fa!l, and perhaps from chill. As there was scarlet fever next door I examined him carefully for symptoms of
this disease, but could find none, nor were there any signs of diphtheria.

\section{Progress of Case.}

I saw him again next day, September r8th, about noon, and was told that he had had a very restless night, but did not complain of any par:-
ticular pain. On :examination I was surprised to find complete motor 
paralysis of the muscles of both upper limbs and of the trunk, and also of the intercostal muscles, thus causing the breathing to be entirely! abdominal. There was also partial paralysis of the lower limbs. No loss of sensation could be detected at any place. The temperature was ror ${ }^{\circ} \mathrm{F}$ pulse r1o, and respirations $3 \circ$. No pain was complained of, but the child was very restless, constantly wanting to be turned from side to side. There was no headache, and the mental powers were perfect; there was no loss of control of the bladder or rectum, no priapism, and no rigidity or twitching of any of the muscles. The pupils were somewhat dilated; and seemed inactive, but equal. There

not difficult, and the speech was clear.

At 7.30 P.M. Of the same day Dr. Barrs of Leeds saw the case with me, when we found that the condition of matters was very similar, except that the paralysis of the legs was more advanced, and the muscles of deglutition seemed somewhat involved, and sensation seemed slightly impaired as regarda delicacy of differentiation. The knee-jerks were absent. The spleen was not felt. The respiration had at this time a most marked resemblance to that seen in a rrog - that is, on inspiration a peculiar disthis this time, any indication of cyanosis, and the number of respirations

At midnight the facial "muscles became involved and speech indistinct; the pulse was faling and becoming rapid (126 per minute and intermittent), but th

At I A.M. (September rgth) the heart failed very rapidly, slight cyanosis appeared, and he died quietly ten minutes later. He was quite cons

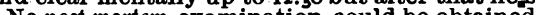

The diagnosis of Landry's paralysis of a descending form was made from (I) progressive, symmetrical, motor paralysis, affecting first the muscles of the neck - the " stiff neck" complained of - then the arms, forearms, chest, legs, etc. ; (2) sensation did not seem at all disturbed until a few hours before death, and even then only slightly; (3) absence of rigidity, twitching, pain, or spasm; (4) mental functions unimpaired, and no loss of control over the emunctories.

It is difficult to see any connection between the slip into the pit and the disease which caused death, as there was no sign whatever of any damage to the spine, and the symptoms do not seem to point to the possibility of the case being one of spinal injury or the results arising therefrom. Nor do I consider it was a case of infantile paralysis, although infantile paralysis has much in common with this disease. The case was an extremely rapid one, as will be seen by noticing the dates.

Little is known as to the pathology of Landry's paralysis, and $I$ would suggest that it is caused by an acute anterior poliomyelitis, somewhat after the nature of that found in infantile paralysis, but instead of the lesions being at spots scattered about the spinal cord, commencing symmetrically at a certain level of the cord, and spreading thenoe rapidly upwards and downwards. In the case above described the lesion probably commenced in the cord about the level of the second cervical vertebra.

\section{TWO CASES OF SEVERE FRONTAL [HERPES.}

By C. HIGGENS, F.R.C.S.,

Ophthalmic Surgeon, Guy's Hospital.

THE two following cases are of sufficient interest to merit publication :

CASE I.-In January, 1900, I first saw Mrs. T., aged 45. She was suffering from a severe attack of left frontal herpes. The eyelids were swollen, and together with the forehead and side of nose covered with scabs, the cornea was ulcerated, and there was severe iritis. By the end of March the swelling had nearly subsided, there was much corneal opacity, and opacity in the vitreous. The pupil was dilated and fixed, tension of eyeball +1 , vision $\frac{6}{36}$ and Jaeger $16 \mathrm{C}+2 \mathrm{D}$. The treatment up to this stage had been hot boracic fomentations, atropine, and attention to general health. She was now ordered solution of pilocarpin nitrate gr. $\frac{1}{2}$ to $\xi j$, to be dropped into the eye three times a day, and a mixture of mercury perchloride. The treatment was persevered with till the end of May, when there was but little improvement. Galvanism was then tried for a fortnight. By the middle of June the inflammatory symptoms had subsided; there was much corneal and vitreous opacity, the pupil was dilated and irregular; the tension of the eyeball above par, and there were small ciliary staphylomata. Vision $=\frac{6}{24} \mathrm{C}-2, \mathrm{~J}$. 14 at $6^{\prime \prime}$. I have not seen the patient since, but had a letter from her in February last, and from her description should sed that the eye is in much the same condition as it was in June.

CASE Ir.-Mrs, H., aged 49, was first sten on March 25 th, 1900. She had suffered from frontal herpes ten.weeks before. On the left side besides much scarring and corneitis with ulceration, there was completemaralysis of the third, fourth, and sixth, and the ophthalmic division of the fifth nerves. There was ptosis, moderately dilated pupil, complete immobility of the eye, and entire loss of sensation over parts supplied by first division of the fifth nerve. On June 6th I heard from the patient's medical man that she had muscular paresis of the right side of the body (that opposite to the affected eve), but sensation was not impaired. I heard no more of the patient until March' 28th, Igor, when she came to see me. The motor paralysis had entirely disappeared; the movements of the eye being perfect; there was some numbness, pain and itching in the forehead; but the sensation of the eyeball itself was normal ; tension of the globe was stightly above par. There was dense partially vascular corneal opacity and some ciliary and conjunctival injection. 'She could count fingers at 3 feet.

\section{AN UNUSUAL SYMPTOM IN SECONDARY SYPHILIS.}

BY A. A. SCOT SKIRVING, F.R.C.S.EDIN., Assistant-Surgeon, Leith Hospital.

DURING the last few years several cases of secondary syphilis of the throat have come under my observation in which itchiness of the fauces has been present. This was not a mere tickling, but a definite itchiness in every way comparable to the ordinary feeling experienced in the skin, and accompanied by a similar desire for counter-irritation by scratching. In two cases this symptom was most marked, and I was greatly struck with the fact that though both patients admitted that there was some pain in the throat, especially on swallowing, it was the itchiness that they complained of most.

In these two cases the desire to scratch the part was most urgent. One of them, who was at that time under treatment at Wiesbaden, used to scratch his throat-and obtain temporary relief-in an ingenious manner by swallowing entire portions of the crust of the "brodchen" supplied by the Badhaus in which he was taking his " cure." The other, a working man, said he sometimes felt " inclined to tear the throat out." Until relieved by local treatment he used to scratch his tonsils with his finger. In these cases the itchiness was felt most over the tonsils, but also over the pillars of the fauces and posterior part of the side of the tongue. The other parts of the mouth and throat were unaffected. In the Wiesbaden case, in addition to congestion, some ulceration was present on one of the tonsils, and thistonsil was the more itchy of the two. In both cases the itchiness had appeared very shortly after the onset of the sore throat, namely, about eight weeks after the appearance of the chancre. Marked cutaneous manifestations were present in the one, none in the other, nor did he afterwards develop any. The latter patient, it may be remarked, had been vigorously treated ever since the primary lesion, the former only on the appearance of the sore throat.

Marked itchiness of the mucous membrane is an interesting symptom, and,'so far as I am aware, has not been referred to in connection with the interior of a cavity. It is of course of common occurrence at the margins of the various openings of the body where skin and mucous membrane meet, as at the urinary meatus, the anus, and vulva. The tongue and the larger part of the buccal cavity are lined with epithelium of the same character as that of the skin. Sensory nerves are abundant, and convey the normal cutaneous impressions of contact, pain, heat and cold, etc., in addition to others of a more special nature which the skin does not possess. In other words, the lining membrane of this cavity is practically moistened skin in some places of a epecialised nature. The wonder, then, seems to be that an abnormal cutaneous sensation, such as itchiness, is not more often met with in connection with mucous surfaces. Probably it is present in a fair number of cases, but is either very slightly marked or is so masked by more urgent symptoms that it fails to attract the patient's attention. 